\title{
$\begin{array}{ll}\text { Research Square } & \text { Preprints are preliminary reports that have not undergone peer review. }\end{array}$ or referenced by the media as validated information. \\ The role of non-coding RNAs in Alzheimer's disease
}

\author{
Ellis Patrick \\ Sathyapriya Rajagopal \\ Hon-Kit Andus Wong \\ Cristin McCabe \\ Jishu Xu \\ Anna Tang \\ Selina H. Imboywa \\ Julie A. Schneider \\ Nathalie Pochet \\ Anna M. Krichevsky \\ Lori B. Chibnik \\ David A. Bennett \\ Philip L. De Jager
}

\section{Video Abstract}

Keywords: Alzheimer's disease, microRNA, lincRNA, Neuritic $\beta$-amyloid plaques and neurofibrillary tangles

Posted Date: November 20th, 2020

DOl: https://doi.org/10.21203/rs.3.rs-112274/v1

License: (c) (i) This work is licensed under a Creative Commons Attribution 4.0 International License.

Read Full License 


\section{Abstract}

Micro-RNAs are small, non-coding molecules no bigger than a couple dozen nucleotides in length. But don't let their size fool you. While they may not code for proteins, themselves, these molecules play an important role in many biological processes by regulating the expression of genes. Recently, they have been implicated in neuron development and neurodegenerative diseases such as Alzheimer's. Now, a recent study published in the journal, _Molecular Neurodegeneration_, has identified a previously unreported association between the amount of a particular microRNA and the accumulation of toxic proteins that characterizes Alzheimer's disease. Late-onset Alzheimer's is characterized by structural changes in the brain and a decline in cognitive abilities, such as memory loss, that worsens with age. Despite the high prevalence of this disease and research efforts, its precise causes are still being worked out. Recent research, though, suggests altered gene expression by non-coding RNAs may play a role. But these past studies were conducted with relatively few subjects and their results have been inconsistent. In an attempt to remedy this, a team of researchers considered molecular profiles from 700 human subjects and set out to evaluate the associations of non-coding RNAs with different elements of diseased brains. They focused on a region of the prefrontal cortex - looking at levels of both micro-RNAs and larger, noncoding RNA. In addition to confirming previously established microRNA associations, the team identified five new non-coding RNAs linked to traits found in the brains of Alzheimer's patients. This work adds to the broad narrative emerging from recent research. That is, molecular changes associated with Alzheimer's likely include alterations in the regulation of gene expression in brain cells. By prioritizing earlier findings, this study will help other investigators focus research efforts on the most important molecules. As regulators of gene expression patterns, further understanding the role non-coding RNAs play in neurological diseases may provide important insights into the development - and potential treatment -- of these disorders. By providing a high-confidence list of molecular associations, this study sets the stage for future research aiming to do just that. 